\title{
Coração sonoro: comunicação, afetos e sociabilidades maquínicas em festas de música eletrônica
}

\section{Resonant heart: communication, affections and mechanical sociabilities in electronic music parties}

Thiago Tavares das Neves

Programa de Pós-Graduação em Ciências Sociais da Universidade Federal do Rio Grande do Norte (PPGCSUFRN), Natal, RN, Brasil

ORCID: 0000-0002-8603-8362

<nevesthiago1@hotmail.com >

\author{
Josimey Costa da Silva \\ Programa de Pós-Graduação em Estudos da Mídia da \\ Universidade Federal do Rio Grande do Norte (PPgEM- \\ UFRN), Natal, RN, Brasil \\ ORCID: 0000-0003-2556-8180 \\ <josimeycosta@gmail.com>
}

\section{Como citar este artigo (How to cite this article):}

NEVES, Thiago Tavares das; SILVA, Josimey Costa da. Coração sonoro: comunicação, afetos e sociabilidades maquínicas em festas de música eletrônica. Revista Famecos, Porto Alegre, v. 25, n. 3, p. 1-18, setembro, outubro, novembro e dezembro de 2018: ID29193. DOI: http://dx.doi.org/10.15448/1980-3729.2018.3.29193.

\section{RESUMO}

Este artigo explora formas de afetar e de ser afetado em festas de música eletrônica com base nas ideias de Spinoza e com o uso do método cartográfico de pesquisa empírica. Afetos, máquinas e sociabilidade são operadores conceituais para análise de aspectos da dimensão comunicacional das festas. Afetos não são exclusivos do plano dos sujeitos; são fluxos de passagens para diversas formas de expressão e afetação, segundo a perspectiva de Deleuze \& Guattari. A comunicação é vista como afeto e fluxo a partir das perspectivas de Morin, Beth \& Pross e Marcondes Filho. Propõe-se que os suportes e ações comunicativas nessas festas incidem diretamente sobre os corpos e alteram o processo de sociabilidade. Assume-se, com suporte em Latour, que os afetos são produzidos e potencializados também por meio das máquinas de música e de comunicação, o que implica em repensar o conceito de sociabilidade e considerar como atores sociais também os participantes não humanos.

\section{ABSTRACT}

This article explores ways of affecting and being affected in electronic music parties, and is based on Spinoza's ideas using the cartographic method for empirical research. Affects, machines and sociability are conceptual operators for the analysis of aspects of the communicational dimension of these parties. Affects are not limited to the subject's plan; they are flows of passage for various forms of expression and affectation, according to Deleuze \& Guattari's perspective. Communication is seen as affect and flow from the perspectives of Morin, Beth \& Pross and Marcondes Filho. We propose that media and communicative actions in such parties directly impact the bodies and alter the process of sociability; also, drawing on Latour, we argue that the affects are produced and potentialized through music and communication machines, which implies rethinking the concept of sociability to consider non-human participants as social actors.

Keywords: Affects. Machines. Sociability 


\section{Introdução}

Jápassava das duas horas da manhã quando odiscjockey (DJ) Steve Angello, a principal atração do King Festival', entrou no palco. House music era o estilo de música eletrônica que saía das caixas de som. Quatro rapazes pulavam de forma intensa perto do palco, dando a impressão, pela forma sincronizadas como dançavam, de que não conseguiam dominar seus corpos. A situação se repetia com os outros corpos: a música os contaminava, as pessoas pareciam escravas do som. Perto do banheiro, localizado no final da pista, mais contágio sonoro, pois não era só na frente do palco que os participantes dançavam e pulavam; ali atrás também, na fila do banheiro. O dono da noite era, de fato, Steve Angello. Sua música afetava o público de forma ativa, que respondia com gritos, danças, pulos e sorrisos. $O D J$ batia palmas, falava às vezes com o público; a interação entre $D J /$ pista e pista/DJ era notável. A sociabilidade manifestada naquela pista era potencializada por ondas sonoras, maquínicas, de alta intensidade.

A cena narrada acima é um exemplo clássico de interação em uma festa de música eletrônica. Assim são esses eventos: corpos dançantes, conectados pela percussão (batida) eletrônica e estimulados por substâncias lícitas e ilícitas. Música, drogas, corpos, dança: tudo é fluxo neste contexto. A música eletrônica/maquínica, ou seja, feita com máquinas eletro-eletrônicas, afeta corpos excitados por drogas, que afetam outros corpos, que respondem ao $D J$ por meio da dança. As festas de música eletrônica podem ocorrer em festivais, em raves, em lugares abandonados, clubes. A música tem que ser a eletrônica e essa é a única regra; o resto é consequência da disposição dos participantes intensificada pelo fluxo sonoro.

$\mathrm{O}$ afeto que movia as pessoas naquela noite é neste artigo entendido como passagem e movimento, como ação e emoção, como fluxo e sentimento. As relações humanas não seriam possíveis sem os afetos. Os afetos estruturam a base da sociedade e da cultura, pois ambas se fundam a partir da relação com o outro. Não existe alteridade sem a mediação dos afetos e isto quer dizer que os afetos são o alicerce da própria existência. Essa condição para a existência pode ser demonstrada inclusive do ponto de vista da fisiologia: o corpo humano, para se manter e se regenerar, tem necessidade de afetar e ser afetado por corpos exteriores ao dele.

1 O King Festival, festival voltado para a música eletrônica, aconteceu nos dias 15 e 16 de novembro de 2013 na cidade de Recife/PE. Foi a primeira edição e contou com grandes executores da música eletrônica conhecidos no cenário mundial. 
Para Spinoza $(1677 / 2010)^{2}$, os afetos são as afecções do corpo, uma ação, uma potência de agir que pode ser aumentada ou diminuída e essa ação pode ser de um corpo sobre o outro ou de um objeto sobre um corpo. Pensar os afetos sob a ótica spinozista é entender como se forma a própria sociedade, dentro de um jogo de afetações em que uns afetam os outros, modificando a si mesmos e aos outros depois de afetarem ou serem afetados.

\section{Spinoza e os afetos}

Para Merleau-Ponty (2006), o ato de sentir é uma comunicação vital com o mundo; não seria possível compartilhar sentimentos no processo de sociabilidade se não houvesse a comunicação entre os sujeitos. Comunicação, nesse caso, remete à partilha, divisão de algo com o outro, o que implica em diferentes níveis de mobilização sentimental. Ao sentir e ao transmitir meu sentimento ao outro, posso modificar tanto a mim quanto ao outro, positiva ou negativamente. A comunicação se realiza e o sentimento é conteúdo transformador entre o eu e o outro. Nesse sentido, sentimentos podem ser considerados como emoções ou afetos, ou seja, são modos de conhecer o mundo e de pensar, pois o corpo é sempre afetado ao sofrer a ação do mundo sobre si e essa ação gera, invariavelmente, algum nível de emoção ou mesmo um sentimento e há sempre a possibilidade de algum tipo de ideação, elaboração consciente ou abstração racional em decorrência. Spinoza (1677/2010) não faz distinção entre sentimento, emoção e afeto e utiliza sempre o vocábulo afeto para referir-se a esse tipo de fenômenos. Para ele, o ser humano não consegue viver livre dos afetos. A sua vontade não é livre, pois há uma relação de dependência entre o indivíduo e os afetos. Isso acontece porque a todo instante o homem é afetado pelo mundo que o cerca. Não há controle das ações do acaso sobre o ser, mas existe uma relação de dependência e causalidade entre o mundo, que causa algo no individuo, e o ser, que causa no mundo. Viver é afetar e ser afetado.

Spinoza falava a respeito dos afetos (affectus) como ação de afetar, como afecção (affectio) do corpo e como a ideia dessas afecções. As afecções são imagens ou marcas corporais que remetem a um estado do corpo afetado e implicam a presença do corpo afetante (o corpo que afeta). São as marcas de um corpo exterior sobre o corpo afetado. Sobre afetação, discorreremos mais adiante neste artigo. Deleuze (2009), ao se debruçar sobre o pensamento de Spinoza, afirma que o filósofo não acreditava em uma ação a distância, pois

2 A maior parte das obras de Spinoza, incluindo a Ética, foram originalmente publicados na Opera Posthuma (OP / Nagelate Schriften (NS), 1677). As edições utilizadas neste artigo são recentes. 
sua ação implicará sempre em um contato e sua afecção será uma mistura de corpos. Esses corpos não são obrigatoriamente humanos; podem ser objetos, animais, corpos materiais inanimados. A affectio é uma mistura de dois corpos, um corpo que age sobre o outro e o outro que vai abrigar a marca do primeiro. Toda mistura de corpo levará o nome de afecção. A afecção é o efeito de alguma coisa sobre o sujeito; as percepções são exemplos de afecções. No seio da afecção, há um afeto. O afeto seria o processo de transição de um estado para o outro, é a passagem vivida, é alguma coisa que a afecção envolve.

O afeto é, por consequência, essa passagem vivida, experimentada, que implica necessariamente um aumento de potência ou uma diminuição de potência. Através das afecções, não só a potência de agir do afeto é aumentada ou diminuída, estimulada ou refreada, mas também as ideias dessas afecções. Os afetos são as diminuições e os aumentos de potência vividos. Por exemplo: quando a potência de agir é aumentada, surge o sentimento da alegria; quando diminuída, da tristeza. É a potência que define a força de um afeto. A potência de agir varia em função de causas exteriores. $O$ afeto é uma ação quando o sujeito é a causa de uma dessas afecções, e uma paixão quando o indivíduo é afetado. Para Spinoza, o corpo humano pode ser afetado de muitas maneiras por corpos exteriores, por objetos, e cabe a cada ser humano julgar, de acordo com seu afeto, o que é bom e o que é mau. Tudo o que acontece no corpo humano deve ser percebido pela mente e todas as maneiras pelas quais um corpo é afetado seguem-se da natureza do corpo afetado e, simultaneamente, da natureza do corpo que o afeta (Spinoza, 1677/2010).

É importante destacar que todo afeto é uma afecção, mas nem toda afecção é um afeto, ou seja, uma afecção é um afeto se tiver um impacto sobre a potência de agir de um corpo. O riso, o tremor, uma lágrima são afecções que remetem ao corpo sozinho, não precisam, obrigatoriamente, de um corpo afetante que cause a mudança de estado, ou aumento/ diminuição da potência para se tornar de fato um afeto. No entanto, para existir um afeto, é preciso haver uma afecção. Uma fotografia, por exemplo, pode afetar um sujeito de diversas maneiras, seja ao trazer uma boa recordação, seja uma má lembrança; um cachorro é afetado pela presença do dono ao abanar o rabo de alegria ou ao morder esse dono, caso esteja com raiva. Spinoza reconhecia o afeto dos animais não humanos, assim como dos humanos. Quando se trata de seres vivos não humanos, os afetos incluem a dimensão do sentir, da percepção, mas não há uma racionalidade sobre isso porque os afetos estão no campo da mera fisiologia, do neural, dos estímulos-resposta. Já no caso dos humanos, os afetos podem ser comandados pela razão. Há, ainda, os afetos dos seres inanimados, os objetos, que operam na lógica da ação, do fluxo e se restringem a isso. Primariamente 
o afeto é fluxo, ação; em seguida, dependendo dos corpos envolvidos, ele vai atuar na percepção e, por último, pode virar um sentimento mais elaborado sob o ponto de vista cognitivo. Nesse jogo de afetação, nenhum dos dois corpos nem o que é afeta nem o que é afetado é passivo, tudo é interação. "A interação se torna comunicação" (Deleuze \& Guattari, 1992, p.183).

A contribuição de Spinoza (1677/2010) é fundamental para pensar a comunicação sob a ótica dos afetos. Quando há comunicação entre dois indivíduos, ambos são modificados, afetados pelo processo e ocorre uma troca, uma partilha como resultado da ação de um sobre o outro. A comunicação é, nesse sentido, equivalente ao processo de transição de estados a que se Spinoza se referia. Um objeto ou um signo, ao agir sobre um sujeito, o modifica; em algum nível, por mínimo que seja, o estado do indivíduo é alterado para que a comunicação efetivamente aconteça. Spinoza reconhecia a existência de apenas três afetos primitivos: a alegria, a tristeza e o desejo. Todos os outros afetos estão relacionados a esses três.

Para Spinoza (1677/2010), os afetos não estão apenas no plano dos sujeitos; antes, são fluxos de passagens, pressupõem transferência, trânsito. As festas de música eletrônica são um campo privilegiado para pensar a impermanência, pois tudo está em fluxo: mensagens, luz, som, drogas, máquinas, pessoas, interações, emoções, sentimentos. As festas transitam entre lugares e durações diversas, entre modas e vinculações efêmeras. O termo rave é de origem inglesa e significa festa espetacular, mas também é o adjetivo entusiasmado. A música eletrônica é geralmente tocada em um volume alto, cabendo ao DJ guiar a vibração dos dançantes. No momento em que ele executa uma música, afeta de alguma forma os corpos dos participantes e altera os seus estados emocionais.

Esse tipo de festa engloba diversos eventos: as raves comerciais, as raves underground e as raves em lugares abertos em contato com a natureza. As comerciais geralmente têm grande divulgação na mídia. São realizadas em arenas, estádios ou locais para shows, trazendo $D J$ 's conhecidos mundialmente. As do tipo underground, em que a divulgação geralmente é pouca e comumente realizada de forma oral, acontecem em lugares abandonados e os frequentadores habitualmente já se conhecem entre si. As raves em lugares abertos ocorrem em praias, sítios, granjas, cujo intuito é de destacar o contato com a natureza.

Há outro tipo de festa de música eletrônica que acontece em casas noturnas (clubes e bares), que são relevantes no contexto desse tipo evento, mas não configuram raves em stricto sensu. É relevante ressaltar que a cena rave começou em clubes; eles fazem parte da história. (Sylvan, 2005). Outro tipo de festa de música eletrônica são os festivais. Boa parte das vezes, os festivais duram mais de um dia, com grande produção e atraindo uma multidão. Pode- 
se citar, como exemplo, o festival de música eletrônica Universo Paralello ${ }^{3}$, que acontece no final do ano no sul da Bahia.

\section{Máquinas e afetações}

Nas festas de música eletrônica, a máquina tecnológica é indispensável; o aparato tecnológico em si é protagonista juntamente com o DJ. Pode ser um computador, sintetizador, sampler ${ }^{4}$, mixer ${ }^{5}$, fone de ouvido, caixas de som. Toda essa maquinaria tecnológica gera a música essencialmente eletrônica. Construída por meio de sintetizadores (instrumento projetado para produzir sons gerados artificialmente) e outras tecnologias decorrentes ou não da microinformática. Este tipo de música sugere ritmo, continuidade, infinitude, circularidade, hipersonoridade, mixagem, novas colagens, afetações diversas. As batidas são intensas e a sensação é de que são intermináveis.

A história dessas comemorações eletrônicas está conectada ao surgimento do house em 1986, nos Estados Unidos, em específico nas cidades de Dallas e Chicago. O house é um estilo de música eletrônica associado à era disco dos anos 1970 com um público de prevalência homossexual e negra. É uma espécie de disco music ${ }^{6}$ misturado com ritmos eletrônicos do início dos anos 1980. De acordo com Simon Reynolds, este estilo cria na pista de dança um ginásio de desejo, uma liberação do êxtase, um espetáculo coletivo de auto-erotismo, muito presente nas discotecas gays durante a década de 1970. (Reynolds, 1999). A batida é exata e cronométrica entre 120 a 130 bpm (batidas por minuto), fazendo uso de muitos sons sintetizados.

Dois anos depois do surgimento do house, o techno (ritmo eletrônico mais sincopado, de batidas intensas) apareceu em Detroit. O techno espalhouse de Detroit para Nova lorque e, logo em seguida, se transplantou para Londres e Tóquio. Como a house music, esta vertente da música eletrônica possui um formato mais extenso e não precisa ser escutado desde o início, além de possibilitar facilmente o processo de mixagem. As batidas variam entre $130 \mathrm{a}$ $150 \mathrm{bpm}$.

3 Mais informações: https://universoparalello.org/pt/

4 Máquina que tira amostra de sons captando, registrando, analisando e reproduzindo ondas sonoras de qualquer natureza.

5 Aparelho que alterna e/ou combina várias fontes de som, de forma a somá-las em um único sinal de saída.

6 Estilo de música eletrônica que teve seu início e apogeu durante a década de 1970, dando origem as discotecas (clubes noturnos onde a música era tocada). Nova lorque foi considerada o pólo da disco music. A discoteca Paradise Garage foi a primeira discoteca dos EUA, com discotecagem do DJ Larry Levan que inaugurou o estilo. Esta vertente de música eletrônica atraía mais o público gay (de cor negra e latinos). Toda essa atmosfera combinada com o lançamento do filme Saturday Night Fever (Os embalos de sábado à noite) que transmitia bem o clima disco da época. 
O techno e o house eram os estilos de música eletrônica mais escutados nas raves e casas noturnas no final da década de 1980 na Europa e nos Estados Unidos. Depois, surgiram diversos estilos de música eletrônica como o trance, o acid-house, o electro, o drum and bass, o tribal house, dentre outros. Cada estilo varia na sua estrutura de acordo com as bpm, velocidade do ritmo de cada gênero musical. As festas de música eletrônica e os estilos desenvolveram uma relação direta e mútua. Algumas festas se dedicam a apenas um estilo. Atualmente, há também o gênero EDM (electronic dance music) na sua tradução literal. A EDM é escutada geralmente em casas-noturnas, grandes festivais de música eletrônica e tem como foco a dança, o entretenimento e o apelo comercial.

A música eletrônica é a protagonista da festa. Age sobre o corpo dos dançantes e do $D J$, afeta a todos de alguma maneira, seja de forma ativa, despertando o afeto da alegria, ou de forma negativa, provocando a tristeza. É nesse cenário que surgem as afetações não são somente entre sujeitos, mas também entre homens e máquinas, que emergem neste contexto indistintamente como atores sociais.

A máquina, na acepção que interessa a este artigo, é um sistema de controle ou de cortes; está relacionada com um fluxo material contínuo, que ela interrompe. A produção do corte de fluxo só acontece se a máquina estiver conectada com outra. Sob essa perspectiva de fluxos e cortes, a definição de máquina extrapola o entendimento de máquina apenas como aparelho industrial/tecnológico. A ideia de fluxo tem uma definição física, como um número de partículas que escoam, por unidade de área, de uma secção transversal de um feixe de partículas. Assim, tem-se fluxo como movimento contínuo de algo que segue um curso. Não obstante o conceito de máquina seja fundamentalmente físico, é a partir do conceito de produção e fluxo que surgem as outras máquinas. Para Morin (2008), existem máquinas físicas, biológicas, sociais. Na máquina, não existe somente o maquinal (repetitivo), há também o maquinante (inventivo); a ideia de máquina comporta os componentes de produção e criação. Dentro dessa compreensão ampliada, o corpo humano pode ser considerado também uma máquina: a boca que corta o fluxo de leite; o nariz que corta o fluxo de ar; o ouvido, o fluxo sonoro. O corpo humano é uma máquina física que realiza trabalho, efetua transformações e produções. Qualquer ser físico que execute trabalho, sofra transformação e produza é uma máquina porque é produção e fluxo.

Guattari (1988) afirma que o inconsciente humano é maquínico, opera como máquina, controla e corta fluxos, assim como tudo ao redor do sujeito: são tão-somente máquinas. Maquinas desejantes, que afetam e são afetadas. Esse inconsciente está atuante em tudo, trabalha no interior dos indivíduos, no viver 
dos corpos, na família, no sexo, no bairro, na escola, nas universidades, nas festas... Sujeito e máquina estão imbricados um no outro. Entra sempre uma parte de subjetividade no seio de todo agenciamento maquínico. Reciprocamente, entra uma parte de sujeição maquínica no seio de todo agenciamento subjetivo. Na sequência dessa proposição, pode-se falar que há uma consonância de ordem tecnológica eletro-eletrônica entre máquinas-músicas e máquinas-corpos mediada por afetos nas festas de música eletrônica. Para mais além da sujeição maquínica que caracteriza a existência humana no mundo, o corpo humano atual é um pouco cyborg também, tecnologizado pelas próteses artificiais, sejam de cunho estético como o silicone para aumentar os seios ou funcionais como os aparelhos auditivos etc. Seriam máquinas corporais (máquinas-corpo) entrelaçadas com máquinas tecnológicas (tecnomáquinas).

Morin (2008) afirma que os indivíduos são seres-máquinas. Ele compreende a máquina como algo que produz e cria, e, nesse sentido, está em movimento contínuo, em fluxo. O ser vivo deve ser entendido como a mais perfeita das máquinas cibernéticas e inclusive o mais perfeito autômato, pois ultrapassa em complexidade, perfeição e eficiência, até a menor das bactérias, a mais moderna das usinas automáticas. É possível compreender a vida como complexo polimaquinal porque comporta, entre todos os sistemas vivos, uma correspondência estrutural e processual de cunho maquínico. Isso, entretanto, não quer dizer que todos os sistemas vivos sejam iguais, indistintos e que se relacionem entre si indiferentemente. As diferenças estão também nas estruturas, processos e especialmente, no sistema límbico (emocional) dos humanos, que difere dos outros seres vivos. Para Damásio (2004), falta aos outros seres vivos as estruturas cerebrais necessárias para representarem em mapas sensitivos as transformações que ocorrem no corpo durante uma emoção.

Além disso, os seres humanos são máquinas com uma capacidade de simbolizar altamente desenvolvida, característica que corta o fluxo dos acontecimentos, permitindo a apropriação psíquica do mundo. Cassirer (1977) afirma que é o símbolo que imputa sentido ao mundo e permite o desenvolvimento da cultura. É inegável que o pensamento e o comportamento simbólico figuram entre os traços mais característicos da vida humana e que todo o progresso da cultura humana se baseia nessas condições. Por meio dos símbolos, o homem compreende, interpreta, articula, organiza, sintetiza e universaliza sua própria experiência, seja no campo da linguagem, da religião, da arte ou da ciência. Por meio do símbolo, o homem produz cultura; o homem é uma máquina simbólica/simbolizante.

Há, então, máquinas técnicas, máquinas humanas e máquinas sociais, se pensarmos em estruturas que cortam e controlam o fluxo dos acontecimentos 
coletivos. A máquina técnica implica um elemento não-humano, que amplifica, prolonga a força do homem, máquina humana. A máquina social tem os homens como peças e os integra, interioriza-os num modelo institucional que abrange todos os níveis da ação, da transmissão e da motricidade. Ela também forma uma memória sem a qual não haveria sinergia entre o homem e suas máquinas técnicas. Uma mesma máquina pode ser técnica e social, mas não sob o mesmo prisma: o relógio, por exemplo, como máquina técnica, serve para medir o tempo uniforme e, como máquina social, serve para reproduzir as horas sagradas, assegurar a ordem na cidade e acionar todo um fluir simbólico ao representar status, procedência, gênero etc.

Há também as máquinas desejantes, que atravessam toda a sociedade: são os elementos microinconscientes, que funcionam também nas máquinas sociais. A máquina é desejante e o desejo é maquinado. (Deleuze \& Guattari, 2010). O desejo é onde o rizoma opera, é aberto, conectável, é a ponte entre os humanos, é o que liga. O rizoma é uma haste subterrânea e difere absolutamente das raízes e radículas. Qualquer ponto de um rizoma pode ser conectado a qualquer outro e deve sê-lo. (Deleuze \& Guattari, 1995).

Nas festas de música eletrônica, toda uma maquinaria está interconectada como um rizoma. Máquinas humanas e tecnológicas estão interconectadas pela música, no mesmo fluxo sonoro e vibrátil, como se fossem uma máquina social desterritorializada, afetando-se mutuamente. A máquina social está espalhada nos gestos do ser humano. $O$ inconsciente é maquínico, trabalha como fábrica e contamina as ações do indivíduo no cotidiano. $O$ termo social é aqui compreendido no sentido proposto por Latour (2012) de associação entre coisas que não são, em si mesmas, sociais. $O$ intuito é não restringir o social aos humanos, mas ampliar a esfera do social às coisas, animais, plantas, máquinas tecnológicas etc. Por esse motivo, Latour define o social como um movimento peculiar de reassociação e reagregação, um tipo de associação momentânea caracterizada pelo modo como duas ou mais partes se aglutinam e assumem novas formas. $O$ social para Latour pode ser um tipo de afetação.

Outra noção importante para a abordagem deste artigo é a de ator social, termo utilizado por Latour (1994) para designar animais, plantas objetos etc., ou seja, tudo aquilo que não for humano e que componha a vida social. Os atores sociais não humanos são privados de alma, mas a eles é atribuído um sentido e, por isso, possuem a capacidade de indicar, de forma confiável, os fenômenos, o que os converte em também atores sociais.

Tendo esses pressupostos, o termo afetação pode ser também um ato ou efeito de conectar, de ligar; como aquilo que afeta e, de alguma forma, une. 
Na observação empírica feita sobre as festas de música eletrônica ${ }^{7}$, foi possível iluminar as afetações encontradas com o conceito de Spinoza (1677/2010) de afetos e afecções, que remete não só ao estado do corpo quando afeta ou é afetado, mas à ação, à transformação, à passagem que os corpos sofrem /agem quando afetam ou são afetados, além de corresponder a todo processo afetivo em que há uma transformação da energia vital do ser. A afetação engloba o afeto e a afecção. A afetação não deve ser confundida com afecção, até porque existem algumas afecções que nem se tornam afetos.

Nas festas de música eletrônica, as afetações podem ser corporais, sonoras, sociais e maquínicas. Na primeira, o corpo humano é afetado por outro humano; na segunda, a afetação se dá por estímulo sonoro; na terceira há um processo de afetação entre seres humanos com humanos e não humanos, reciprocamente, e na última, os humanos são afetados exclusivamente por máquinas. As afetações são inerentes a todos os tipos de festa, contudo, nas festas de música eletrônica, há uma consonância forte entre as afetações maquínicas e sonoras por causa da música essencialmente tecnológica, produzida por máquinas tecnológicas (tecnomáquinas) que afetam corpos ciborgues, modificados pela tecnologia e também com próteses dentro de si. Há encontros.

Deleuze (1968) exemplifica dois tipos de encontros: no primeiro caso, encontro um corpo cuja relação se compõe com a minha, produz em mim uma afecção boa, desperta em mim o sentimento de alegria; no segundo, encontro um corpo cuja relação não se compõe com a minha, que não traz nada de útil à minha natureza, e, nesse sentido, é nocivo e me afeta com tristeza. (DELEUZE, 1968). Quando encontro com alguém ou algo, afeto-o; e para que haja afetação, é indispensável o encontro. Spinoza (1677/2010) dizia que temos sempre que buscar os bons encontros, aqueles que aumentam nossa potência de agir e nos preenchem de alegria. Os bons encontros são raros em nossas vidas, por isso a procura dos indivíduos por festas, diversão, música, dança.

No ato de viver, todo corpo acaba sendo afetado por algum encontro. $\mathrm{O}$ próprio mundo nos afeta globalmente e essa afetação é necessária para permitir que ocorra uma comunicação entre o eu e o mundo. Para comunicar, é preciso afetar, de modo que todo processo de comunicação é também um processo de afetação; se me comunico com o outro, modifico-o e o outro modifica algo em mim. A afetação mútua entre pessoas/objetos pode transformar-se em

7 Os dados dessa pesquisa é o resultado de uma tese doutoral em Ciências Sociais da UFRN. Foram visitados dois festivais de música eletrônica um em Recife/PE, o King festival que ocorreu nos dias 15 e 16 de novembro de 2013; o Dream Valley realizado nos dias 14 e 15 de novembro de 2014 em Penha/ SC e a PAJUX, uma festa de música eletrônica que aconteceu em 20 de fevereiro de 2016 numa casa noturna em Natal/RN. 
interação ou comunicação, mas nem toda afetação é comunicação se não resultar em uma alteração mutuamente implicada e mais ou menos comum para os participantes.

Há também as afetações comunicativas, elas acontecem porque o nosso corpo é uma mídia. O ser humano pode ser compreendido não só como receptor das informações provenientes do meio, mas como uma rede de comunicação que emite signos continuamente, ao mesmo tempo em que os recebe do seu ambiente. O corpo humano é a mídia primária por ser a primeira forma de comunicação do sujeito com o meio (Beth \& Pross, 1990), por ser possuidor de uma riqueza comunicativa impressionante. Suas expressões, gestos, cheiros, olhares, toques e maneiras de agir criam uma trama de significados inserida em ambiente natural, social e cultural. Essa trama desvela um corpo visualizado como um pergaminho, que precisa ser lido e interpretado pelos outros sujeitos para ser socialmente e culturalmente reconhecido no mundo que o circunda.

O corpo é o começo e o fim de toda comunicação, éo primeiro instrumento de afetação e vinculação com outros seres humanos. É linguagem e, ao mesmo tempo, produtor de inúmeras linguagens com as quais o ser humano se aproxima de outros seres humanos, se vincula a eles, cultiva o vínculo, mantém relações e parcerias que são edificadas culturalmente e socialmente por causa da experiência do corpo no mundo e da sua atuação com o outro (Baitello Jr., 2005). Nas festas de música eletrônica, corpo expressivo é o corpo da comunicação, aquele que se manifesta, demonstra-se, põe-se para fora durante a ação e durante o processo da afetação. É um corpo que só tem sentido se for ativo, potente.

\section{Os afetos nas festas}

A comunicação é um fluxo de alta intensidade nas festas de música eletrônica, principalmente entre o público/DJ. Há, no entanto, outro fluxo comunicativo que é igualmente intenso, embora menos entendido como tal: a conexão do tipo eletro-físico entre público/caixas de som. No King Festival, por exemplo, a afetação sonora foi sensivelmente significativa. A apresentação da dupla australiana de DJ's NERVO afetou o público de forma ativa. As $D J$ 's australianas falavam algumas frases e executavam coreografias com as mãos. A plateia era guiada pelo som de NERVO e a maioria das pessoas cantava suas músicas. A afetação era recíproca. As artistas afetavam o público, que afetava as artistas. Sua apresentação foi uma demonstração de que as afetações sonoras são relações afetivas entre o sujeito e determinado tipo de música ou som e vão além da fruição sensorial em alguns casos, principalmente quando a música já é conhecida pelo individuo e aumenta sua potência de agir. 
No mesmo festival, eram notáveis também as afetações principalmente entre máquinas humanas e tecnológicas. Afrojack, umas das principais atrações da festa e que iria encerrar o festival, atrasou mais de duas horas. Algumas pessoas usavam freneticamente seus celulares, postando mensagens; outras fotografavam, filmavam. Quando o DJ chegou, sua música empolgou os dançantes e várias pessoas se aproximaram das caixas de som, tantas que logo não havia mais espaço ali. A afetação pela máquina de som naquele instante não deixava de ser também uma afetação sonora, mas as afetações maquínicas pressupõem associações sensíveis entre os sujeitos e determinadas máquinas, sejam elas quais forem.

Já as afetações comunicativas extrapolam a mera troca de informações ao criar comunhão por meio de atividades ritualizadas e simbólicas entre os atores sociais. Esse tipo de afetações também cartografada no King Festival teve manifestação especialmente notável durante o set de Afrojack. Pulos se misturavam com passos de dança, cada um respondia aos estímulos da música à sua maneira. No entanto, um corpo numa pista de dança, ao sofrer a ação da música eletrônica, realiza passos que podem ser imitados até de forma mimética por outro participante. Isso ocorreu de forma que, em alguns momentos, o movimento se espalhou para um grande número de pessoas de maneira contagiante. Os participantes se enxergavam uns nos outros. Corpos afetados se comunicavam por meio da dança, de beijos ou de sorrisos, em resposta aos estímulos sonoros.

Bataille (1992, p.104) sugere que a "existência é comunicação - e que toda representação da vida, do ser, e geralmente de 'qualquer coisa', deve ser revista a partir daí." Segundo a etimologia, a palavra comunicação vem do latim communicatio e significa estabelecer uma relação com alguém, mas também com um objeto cultural. Os indivíduos estão entrelaçados na e pela comunicação desde sua história filogenética. As moléculas, as células, os corpos tecem juntos uma teia comunicacional com o ecossistema, estão imbricados nos organismos e na sociedade. A comunicação abraça dimensões físicas, químicas, biológicas, sociais, históricas, filosóficas, psicológicas e culturais. É a espinha dorsal da vida e pressupõe, necessariamente, partilha.

São diversos os fatores que favorecem o estabelecimento de afetações comunicativas nas festas de música eletrônica. Há uma partilha do gosto sonoro, da forma de dançar, da vibe ${ }^{8}$, como os frequentadores costumam falar. A música é especificamente registrada por todo o corpo. A interação ocorrida entre sons e corpos será sempre parte de um resultado de respostas apreendidas, de

8 Energia, vibração. 
disposições individual ou cultural. (Gilbert \& Pearson, 1999). Talvez por isso, por alguma incorporação mnemônica de práticas ancestrais, a música eletrônica cria um cenário de excitação grupal e ressonância rítmica, em que a experiência individual se torna coletiva e todos os presentes são varridos por umespiral desom.

Ao citar Nietzsche em um dos seus textos, Deleuze (1998) faz uma apologia à inteligência Techno, atribuindo um lugar à música eletrônica no mundo contemporâneo ao trazer as problemáticas do tempo, do silêncio, da síntese e da técnica. A música eletrônica é uma produção sonora em que a relação homem-máquina/órgãos-silício vai produzir novas músicas técnicas como puros blocos de tempo ou cristais de tempo. Para Nietzsche (1891/2007) o homem da extrema modernidade é o homem técnico, em quem a diferença entre o sujeito e máquina é turva.

Na realidade da cena de música eletrônica, o ser humano está cada vez mais ligado às máquinas, aos sintetizadores. Há uma conexão do biológico com o silício que permite falar de uma conexão social no sentido atribuído por Latour. A música inteligente, a inteligência Techno, é filha legítima da produção sonora a partir de uma matriz intensiva onde o silêncio, com sua intensidade zero, distribui os elétrons, as vibrações das partículas. O barilho de fundo do choque de elétrons é a mat eria prima de toda a produção sonora. O silêncio é o grande ordenador do plano de composição e do plano de consistência sonora. Ele precipita densidades. (Deleuze \& Manganaro, 1998).

Para os participantes das festas de música eletrônica, principalmente nos festivais e raves, parece que há algo que remete ao cosmos, feito de forças sonoras inaudíveis. Nesse processo de produção sonora, a música eletrônica exprime no seu mais alto grau a temporalização do mundo, a densificação das impressões de sensações e simultaneidade de linhas de realidades conexas múltiplas. O cosmos é sonoro e a Terra sua música. É como se os $D J$ 's tentassem buscar a reprodução desse som cósmico. Os físicos chamam esse som de barulho de fundo, irradiação original, choque de elétrons, de uma produção sonora de caráter abissal, remissiva a uma dimensão temporal e espacial de som do cosmo em expansão.

A experiência de escuta da música eletrônica requer certo nível de concentração e foco. O ouvinte se torna parte do processo de criação musical no momento em que ele, ao dançar ou emitir alguma reação na pista de dança, guia o $D J$ no processo de construção de uma nova música. De acordo com alguns $D J$ 's, são os dançantes que mandam na música. A pista é o termômetro; por meio dela, dos movimentos e das reações que os dançantes emitem, o $D J$ sabe se a música que colocou realmente afetou os participantes de forma positiva ou não. Pode-se falar aqui de uma afetação sonora mediada pela música e ativadora da 
potência de agir daquele corpo individual e social dançante, potência essa que aumenta a experimentação da alegria entre eles.

\section{Uma sociabilidade maquínica}

A palavra sociabilidade é derivada do latim socius, aquilo que "se associa, aliado, algo que acompanha, segue"e tema mesma raiz do termo social. A tradição sociológica, no entanto, restringe o social aos humanos para se referir, geralmente, a qualquer tipo de comportamento ou atitude, influenciado por experiências passadas ou presentes do comportamento de outras pessoas.

Para Latour (2012), a palavra geralmente é usada para tratar aquilo que já está reagregado e age como um todo. Da maneira como o concebe, entretanto, o social designa algo que se associa e pode, depois, se desassociar; não é preciso durar. O social é algo que está em movimento, um alvo móvel que pode conectar-se e desconectar-se. Esse algo é um ator social que pode ser um objeto, um animal, um ser humano; basta ter a habilidade de associar-se a outra coisa. Os atores sociais são mediadores que engendram outros mediadores e, daí, surgem novas e imprevistas situações e vão se traçando cartografias, redes. O que se tem é uma rede em que há movimento, deslocamento, transformação, translação, registro entre os atores. Latour denomina a esse conjunto de possibilidades e práticas de "teoria do ator-rede ou ANT", em que o social é o nome de um tipo de associação momentânea caracterizada pelo modo como se dá a aglutinação ao assumir novas formas.

Esse social pressupõe fluidez, afetações, movimentos; é fluxo assim como a máquina e é dessa acepção que decorre a perspectiva de uma sociabilidade que não ocorre só entre humanos; coisas, animais também se podem sociabilizar. Se nos estudos sociológicos mais ortodoxos, a atividade sempre esteve situada no campo dos sujeitos, a intenção aqui é entender a sociabilidade como uma capacidade que os objetos, os animais, os humanos tem de se associar/conectar-se e se desassociar/ desconectar-se em constante fluxo, passando por diferentes combinações.

Nas festas de música eletrônica, como já relatado, pode-se visualizar esse tipo de sociabilidade. Pessoas, caixas de som, drogas, $D J$ 's, telões de LED, banheiros, aparelhos de celular, todos compõem o cenário em que se desenvolvem as afetações no sentido dessa sociabilidade ampliada. Nelas, vários atores sociais se encontram, associam-se, combinam-se, de modo que se pode falar de uma sociabilidade maquínica, em que coisas e pessoas estão interconectadas em fluxo. O movimento é uma constante, os sujeitos dançam sozinhos, acompanhados (raros casos), ao lado das caixas de som em que 
milhões de decibéis fazem tremer o corpo todo. A imagem abaixo ilustra o que foi dito:

\section{- Figura 1 - Garota dançando ao lado da caixa de som no King Festival}

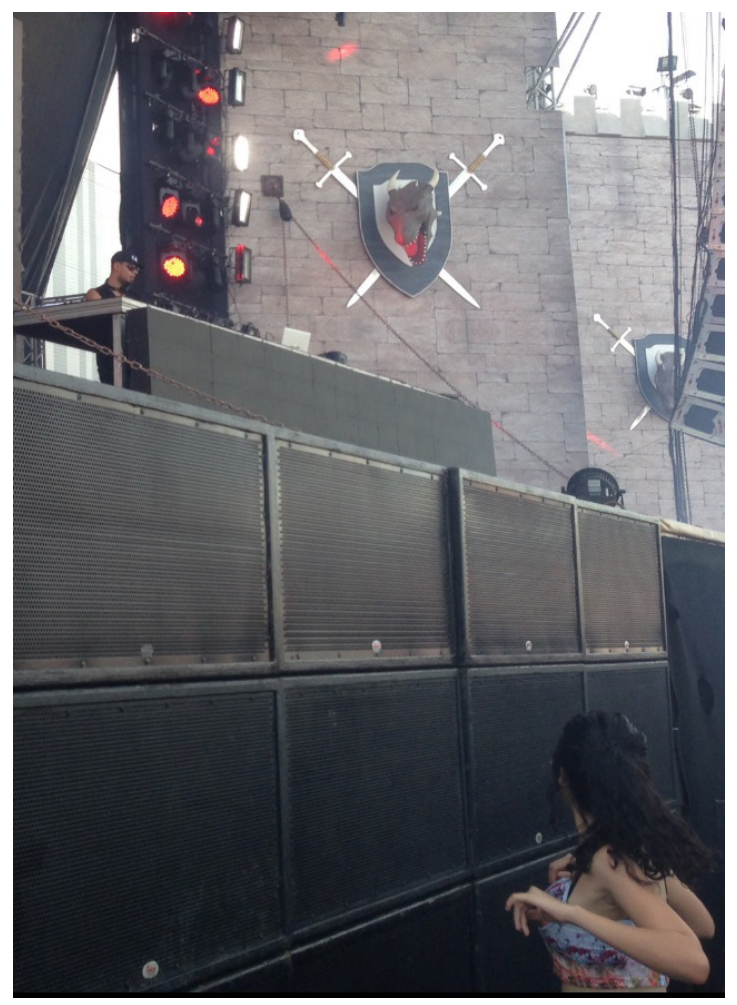

Em momentos assim, o indivíduo se funde à caixa de som como se compusesse com ela uma só entidade. A moça da foto responde aos estímulos sonoro-tecnológicos com sua dança, seu corpo vibra na mesma frequência da música. Seu corpo é uma extensão da caixa. Ou será a caixa uma extensão do seu corpo? As fronteiras claras entre corpo humano e a tecnologia desaparecem do ponto de vista da interação social. É tudo máquina, fluxo e é por meio dos afetos que essa associação acontece. Objetos agindo sobre pessoas, que agem sobre objetos, pessoas agindo sobre pessoas e objetos, sobre objetos: um círculo de afetação onde tudo é ação/reação e em que, às vezes, acontecem os encontros felizes a que Spinoza (1677/2010) se referia.

As afetações ocorridas nas festas de música eletrônica demandam especular-se qual seria o sentido dos afetos na realidade contemporânea. $\mathrm{O}$ que expressam? O que significam? Se a produção de sentido é admitida como 
um fenômeno ${ }^{9}$, no momento em que se expressa, ela sai de si, põem-se para fora, produz-se no decorrer do acontecimento. O sentido não existe a priori, não é algo que está lá por antecipação, mas algo que se constrói no evento do acontecer. Os acontecimentos não possuem um sentido, eles são o sentido. Sentido não está nem nas coisas nem nos seres, mas na sua fricção, no seu atrito, ele é a interseção de vários comportamentos (Marcondes Filho, 2014). Ou seja: é fluxo. Como os afetos.

O sentido é a produção da realidade, o seu acontecer; os afetos contemporâneos e, talvez, atemporais, são os encontros entre os humanos/nãohumanos e o mundo; seu sentido é o ato de conectar, de associar na esfera do mundo vivido. Um afeto é a comunicação em processo, define-se em seu próprio fluxo, em seu movimento como dinâmica dos seres e das coisas, como potência criadora, como a própria criação em ato. A associação entre seres humanos e máquinas eletrônicas, melhor dito, entre máquinas-corpo e tecnomáquinas, cria sentido para os participantes da associação e origina um fenômeno particular que é, ao mesmo tempo, universal, uma vez que a existência social humana se dá em um mundo de técnicas e objetos produzidos e perpetuados culturalmente desde o início da humanidade.

Destacar essa associação tem o intuito de promover uma ética da técnica, em que as afetações entre os humanos, os não-humanos e entre ambos possibilitem a existência de uma realidade criadora, inventiva, produtiva. Uma realidade permeada pelo desenvolvimento educacional, econômico, político, social, cultural, ecológico e humano, acima de tudo. Ética que permita o desvelamento do homem, de um novo homem, com sua matriz arquetípica original, mas atravessado pela tecnologia, por fios e carne, silício e sangue. Um cyborg de fato, porém com uma sempre presente vontade de se conectar, vontade de se associar, criar laços, produzir, afetar, comunicar, simbolizar, imaginar e, porque não, amar.

\section{Referências:}

BATAILLE, Georges. A experiência interior. São Paulo: Editora Ática, 1992.

BETH, Hanno; PROSS, Harry. Introducción a la teoria de la comunicación. Barcelona: Anthropos, 1990.

\section{CASSIRER, Ernst. Antropologia filosófica: ensaio sobre o homem - introdução a}

9 Fenômeno é compreendido aqui como aquilo que existe não só exteriormente, como algo palpável, concreto e social, mas também para o ser que percebe tem um significado idiossincrático. O fenômeno se revela durante o acontecimento, é expressado, posto para fora. 
uma filosofia da cultura humana. São Paulo: Mestre Jou, 1977.

DELEUZE, Gilles. Cursos sobre Spinoza (Vincennes, 1978-1981). Fortaleza:

EDUECE, 2009.

; GUATTARI, Félix. Mil platôs - capitalismo e esquizofrenia 2. Vol.1. São Paulo: Editora 34,1995.

O anti-édipo: capitalismo e esquizofrenia 1. São Paulo: Editora 34, 2010.

O que é a filosofia? Rio de Janeiro: Editora 34, 1992.

DELEUZE,Gilles;MANGANARO,Jean-Paul.DeNietzscheàlaTechno:Manifeste pour les machines-penséesàvenir.Paris, 1998.parRichardPinhas.Disponívelem:<http:// www.webdeleuze.com/php/texte.php?cle=102\&groupe=Bibliographie $\% 20$ et\%20mondes\%20in\%E9dits\&langue=1 >. Acesso em: 2 fev. 2016.

GILBERT, Jeremy; PEARSON, Ewan. Discographies - dance music, culture and politics of sound. New York: Routledge, 1999.

GUATTARI, Félix. O inconsciente maquínico - ensaios de esquizo-análise. Campinas, SP: Papirus, 1988.

LATOUR, Bruno. Reagregando o social - uma introdução à teoria do Ator-Rede. Salvador: Edufba, 2012; Bauru, São Paulo: Edusc, 2012.

MARCONDES FILHO, Ciro. FILHO, Ciro Marcondes (org.). Dicionário de Comunicação. 2. ed. São Paulo: Paulus, 2014.

MERLEAU-PONTY, Maurice. Fenomenologia da percepção. São Paulo: Martins Fontes, $1945 / 2006$.

MORIN, Edgar. 0 método 1 - a natureza da natureza. Porto Alegre: Sulina, 2008.

NEVES, Thiago T. Afeto. In: FILHO, Ciro Marcondes (org.). Dicionário de Comunicação. 2. ed. São Paulo: Paulus, 2014.

NIETZSCHE, Friedrich Wilhelm. Assim falou Zaratustra. São Paulo: Editora Martin Claret, 1891/2007.

REYNOLDS, Simon. Generation Ecstasy - into the world of techno and rave culture. New York: Routledge, 1999.

SPINOZA. Ética. Belo Horizonte: Autêntica, 1677/2010.

SYLVAN, Robin. Trance formation - the spiritual and religious dimensions of global rave culture. New York: Routledge, 2005. 
Recebido em: 17/11/2017

Aceito em: 28/05/2018

Dados dos autores:

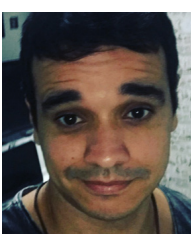

Thiago Tavares das Neves | nevesthiago1@hotmail.com

Universidade Federal do Rio Grande do Norte

Doutor e Mestre pelo Programa de Pós-Graduação em Ciências Sociais da UFRN.

Endereço do autor:

PPGCS - Centro de Ciências Humanas, Letras e Artes - UFRN, Sala 430

Campus Universitário

Av. Senador Salgado Filho, 3000 - BR-101, Km 92

Lagoa Nova

59.078-970 - Natal/RN

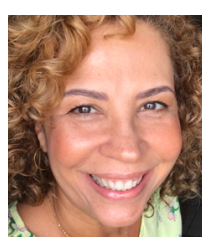

Josimey Costa da Silva | josimeycosta@gmail.com

Universidade Federal do Rio Grande do Norte

Pós-Doutora em Comunicação Social pela ECOPOS-UFRJ e Doutora em Ciências Sociais/Antropologia pela PUC/SP. Professora do Departamento de Comunicação Social da Universidade Federal do Rio Grande do Norte (Decom-UFRN), atuando na Pós-Graduação em Estudos de Mídia (PPgEM-UFRN) e na PósGraduação em Ciências Sociais (PPGCS-UFRN).

Endereço da autora:

Secretaria Acadêmica do Programa de Pós-Graduação em Estudos da Mídia, Laboratório de Comunicação, $1{ }^{\circ}$ andar.

Campus Universitário

Lagoa Nova

59.078-900 - Natal/RN

Contribuições dos autores: Ambos, autor e autora, fizeram contribuições substanciais para concepção, desenvolvimento, redação e revisão crítica do trabalho; e aprovação final da versão para publicação.

Este artigo é licenciado sob forma de uma licença Creative Commons Atribuição 4.0 Internacional (CC-BY). 